$\mathrm{Oz}$

$1-1-1995$

\title{
Compare and Contrast: Mark Robbins' Borrowed Landscape
}

Pat Morton

Mark Robbins

Follow this and additional works at: https://newprairiepress.org/oz

Part of the Architecture Commons

(c) $19 \Theta$

This work is licensed under a Creative Commons Attribution-Noncommercial-No Derivative Works 4.0 License.

\section{Recommended Citation}

Morton, Pat and Robbins, Mark (1995) "Compare and Contrast: Mark Robbins' Borrowed Landscape," Oz: Vol. 17. https://doi.org/10.4148/2378-5853.1273

This Article is brought to you for free and open access by New Prairie Press. It has been accepted for inclusion in Oz by an authorized administrator of New Prairie Press. For more information, please contact cads@k-state.edu. 


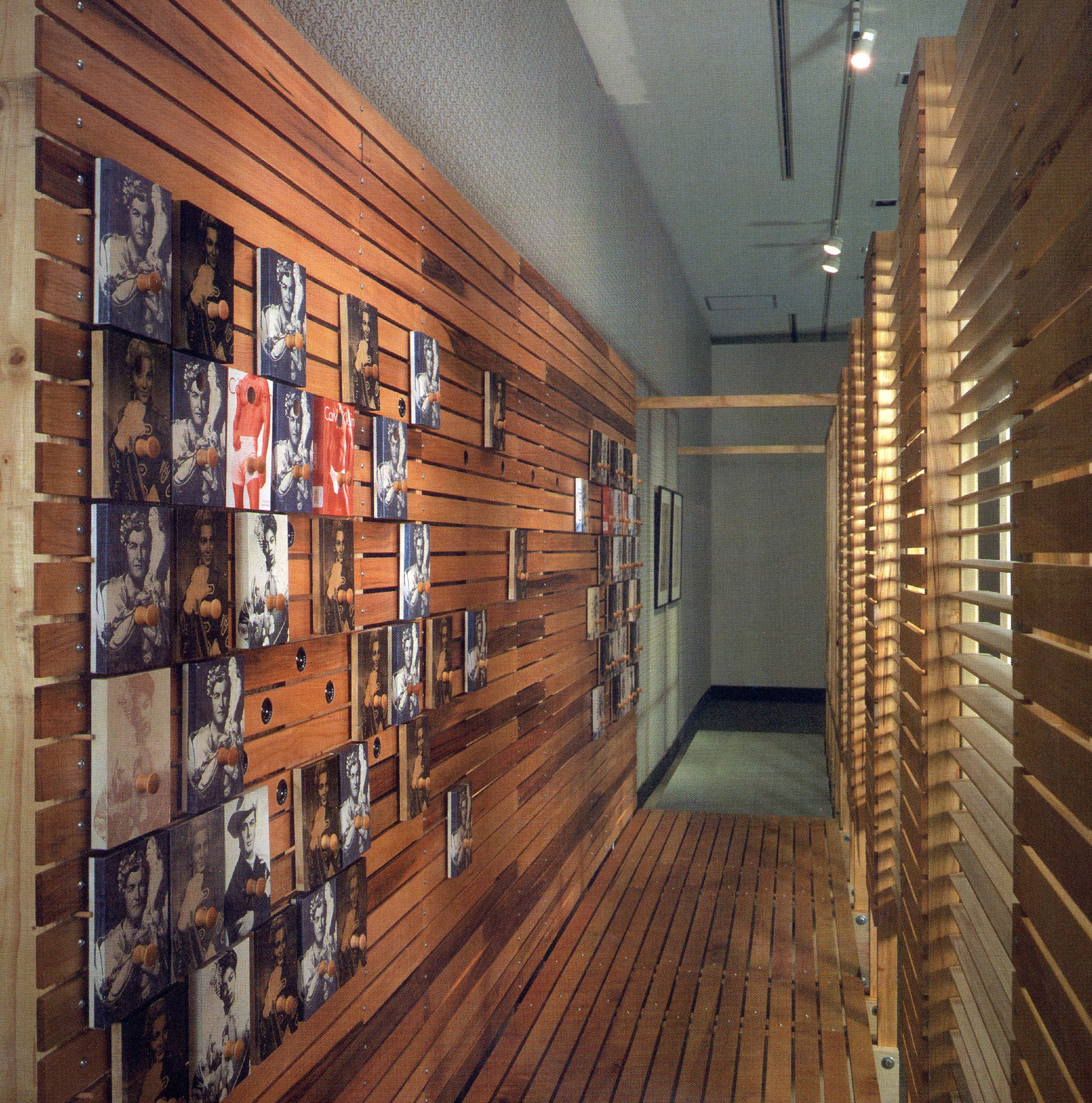


Shakkei, or borrowed landscape, is the Japanese art of visually incorporating distant elements of the landscape into a garden design. In a shakkei garden, a tableau contained within the garden integrates a far view of mountains, trees, or the horizon. The landscape outside the garden is "borrowed" to create the illusion of an infinite expanse of space and view. At Shugakuin Palace outside Kyoto, for example, the mountains surrounding the palace grounds form a visual terminus for the view starting at a lake perched on the mountain side. Foreground and background make a seemingly endless flow of landscape to the horizon and distant and near elements are visually unified. The middle ground is effaced, sutured over by the integration of "artificial" garden and "natural" landscape.

In Borrowed Landscapes-36 Views, Mark Robbins translates the shakkei technique into a strategy for appropriating elements from Japanese and American culture and for placing them in evocative juxtapositions. Robbins uses his sensibility as a gaijin (stranger) in Japan to assemble fragments borrowed from Japanese and American popular culture, from street life, from high art and architecture, and from the Saitama Museum itself into a paradoxical, multi-layered construction. $\mathrm{He}$ also employs shakkei to alter the relations of viewing between museum-goer and museum installation, between viewer and object. In Borrowed Landscapes, the viewer is on display within
Robbins' constructions and is as accessible to the gaze as the objects in the vitrines. Shakkei, in this work, operates as a device for reconfiguring the visual economy that operates within the museum setting and for disturbing the conventional relationships between the spectator, the displayed object, and the exhibition environment. Robbins reinstates a middle ground of ambiguity when he borrows objects and modes of seeing that do not "properly" belong in a museum and when he creates affinities between things that are usually separated into "exotic" and "normal" categories.

Whereas traditionally conceived shakkei gardens create a seamless, unified whole out of the "borrowed" landscape and the constructed garden, Robbins heightens the difference between the juxtaposed components in his installation. He takes materials, spatial relations, and found objects that are laden with culturally specific associations (the Louis XIV chair and the Hiroshige prints, for example) and dissolves their univocal significance by means of comparison. This technique recalls surrealist collage as practiced in the journal Documents and in Meret Oppenheim's constructions, in which ordinary things are defamiliarized by their proximity to unlike objects or by their fabrication in unconventional materials. Robbins is not using juxtaposition to produce purely absurd effects, but in order to explore the affinities and mutual influences as well as the differences between Japanese and
American culture. He contrasts stereotypical images of "Western" and "Eastern" sexuality, design, and tradition to distance them from their easy meanings and to force the viewer to reconceptualize their signification. The shoji screens set into the horizontal brick plane, for example, radically recontextualize the associations of both brick as a load-bearing material and shoji screens as space-defining elements. The unexpected proximity of rice paper screens and brick produces an effect of unfa- miliarity on which Robbins plays throughout Borrowed Landscapes. A similar operation of comparing and contrasting the "natural" and the "artificial," "Eastern" and "Western," occurs in Robbins' deployment of Japanese and American scenes, exemplified by Hiroshige's "Thirty-Six Views of Mount Fuji" and by the twelve souvenir plates from American tourist sites that are housed in the long vitrine. The conceptual equivalency between these popular images closes the foreigness gap, on

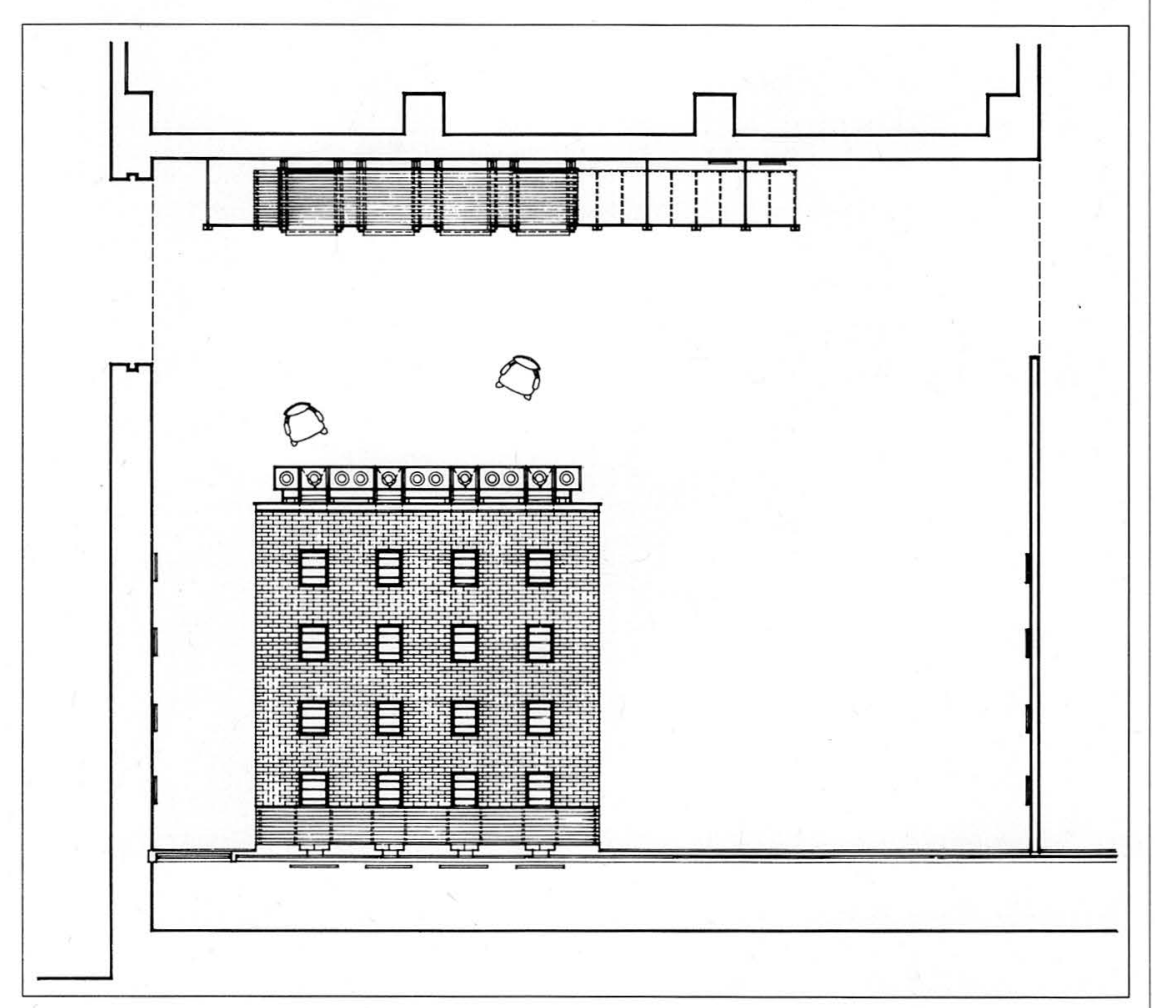




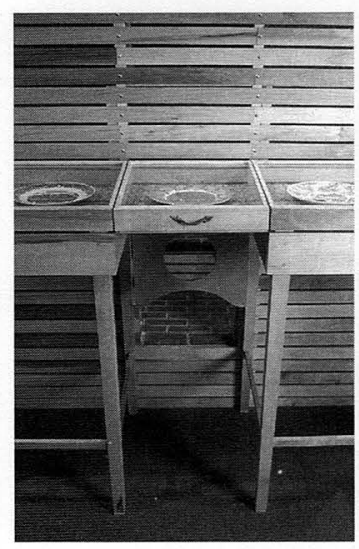

both sides of the Pacific, between what might seem native and what alien. Robbins explores the mutual influences and two-way flow of appropriation between "East" and "West" by exhibiting Meiji period "Western" nudes and the type of Edo period print that inspired the Impressionists.

Robbins' uses the shakkei technique to transform the visual economy of the exhibit itself. Throughout the installation, the museum-goer can manipulate her views of the displays and of the other people in the space. The "ThirtySix" views refer to these multiple modes of viewing, as well as to Hiroshige's famous print series. The brick and wood planes that define the exhibition's different spaces also frame glimpses of spectators' body parts and
This vitrine holds a series of twelve souvenir plates from American tourist sites, both Glen and buildings like the Little White House; a celebration of minor sites. Sections of the underside of these cases are paneled with red-tinted copies of Hiroshige woodblocks and angled mirrors. In form these recall vanity tables. As the hinged segments of the museum cases are opened, die cut aluminum panels are shifted from the orientation of the elevation to plan. These circular mattes now isolate the views of one's own feet rather than groin.

This double-sided vitrine occupies the space made in between the two sets of figural pieces; the slat-wall and a long, thin, wooden structure. In this loosely defined space are two reproduction Louis XIV chairs, of bleached white wood and satin upholstory. They have been mounted on industrial casters and can move throughout this "room." They insert a high European domestic presence, as alien and ersatz as in America, into the gallery. "natural wonders" such as Snow Ball Room at the Great Ice Cave and the gorge at Watkins

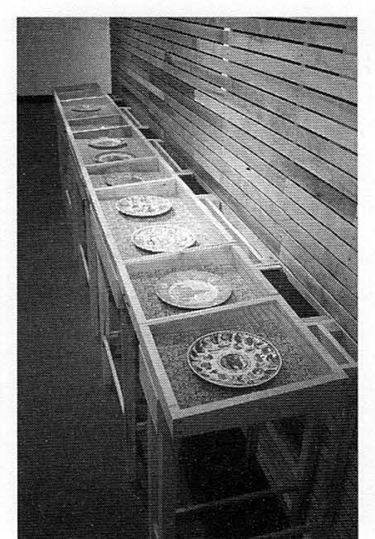

mirrored images of the viewer's own body. Voyeurism is the subtext for the conditions of viewing in which the spectator participates and is caught, the illegitimate modes of seeing usually prohibited by the museum's controlled ocular system. Robbins offers the viewer "bait" in the form of interactive pieces and in the form of glimpses of other viewers. The observer who lifts panels to "peep" through loupes at erotic etchings, Manga porn images, birds, and botanical drawings is herself displayed to other viewers through shuttered panels. Museum viewing is doubled by the erotics of the forbidden gaze, the taboo character of which is intensified by the fetishized male bodies on exhibition. The affinities and differences between the painted Western female nudes, the male Euro- pean bodies, and the male Japanese bodies refer to the classical tradition of the nude, but equally call into question the de-sexualization of the body in the museum context and its suppression of homoeroticism.

By restoring the middle ground to the conceptual and physical construction of this installation, Robbins erodes the "aura," in Walter Benjamin's term, or aesthetic distance with which the museum endows the displayed object. We cannot maintain a disengaged, aesthetic attitude toward these objects, which transgress the neat segregation of the alien from the normal. The ambiguity produced by reciprocal appropriations and mixtures of Japanese and American culture, ordinarily erased by a facile East vs. West polarization, comes to the fore in this work. The thrill of recognition and the frisson of strangeness come from objects and situations that cannot be accommodated within the usual stereotypes and oppositions. By employing stereotypical imagery in decontextualizing juxtapositions, Robbin tantalizes us with the familiar while he simultaneously undermines our preconceptions.

Project Team: Phillip L. Rudy, Thomas Pitzen, Scott Sorli, Melissa Sohrook, Tatsuya Yamazaki, Stephen Cawronski, Andrew Keller, Jim McCool, John Eberhart, Timothy Mizieko, Scan Murphy, Nils Eddy.
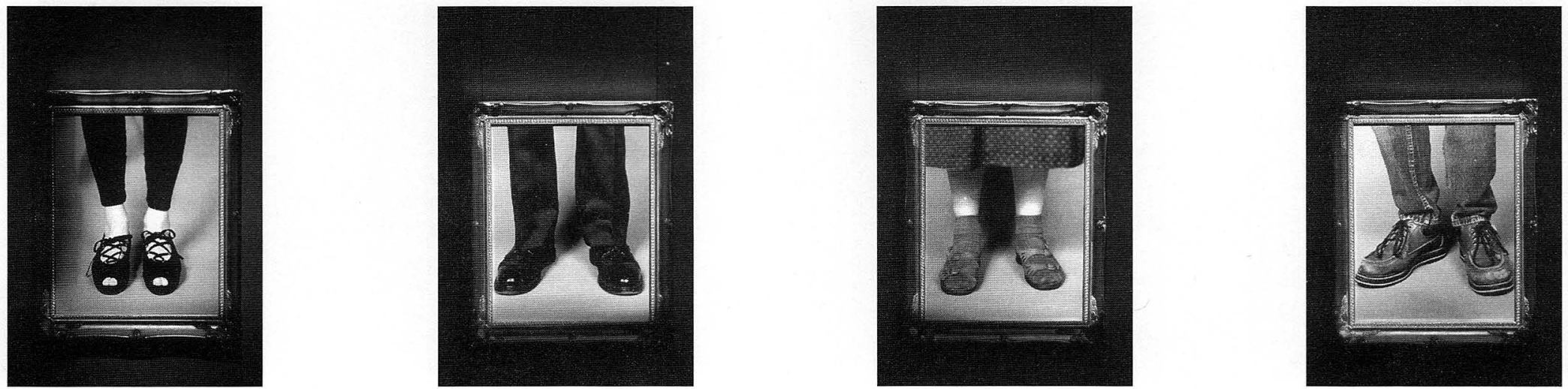


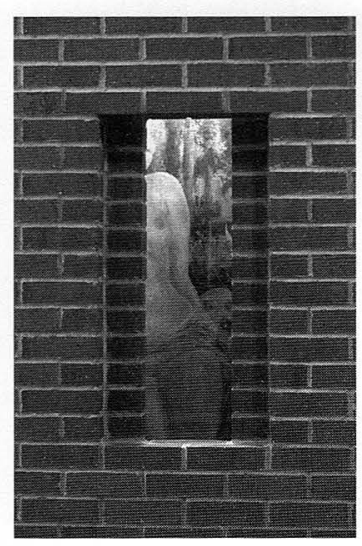

Formally the piece is made up of a series of horizontal and vertical planes either surfaced with wooden slats or brick veneer, incorporating selected pieces from the Saitama Museum collection. Three spaces are defined by a brick wall which wraps the wall and floor and the wooden passageways which opposes it. Through their materiality of form, these building fragments evoke both a room and public square, blurring the distinction between interior and exterior conditions. This formal strategy — of making two strongly defined edges which create a third ambiguous in-between space-is reinforced by the addition of objects drawn from a domestic or institutional context.

The brick veneer which covers three larges surfaces refers to the Mieji period, a time when Japan opened its borders and imported culture flourished. This fascination included literary forms, painting, and music, as well as an architecture identified with classicism and masonry.



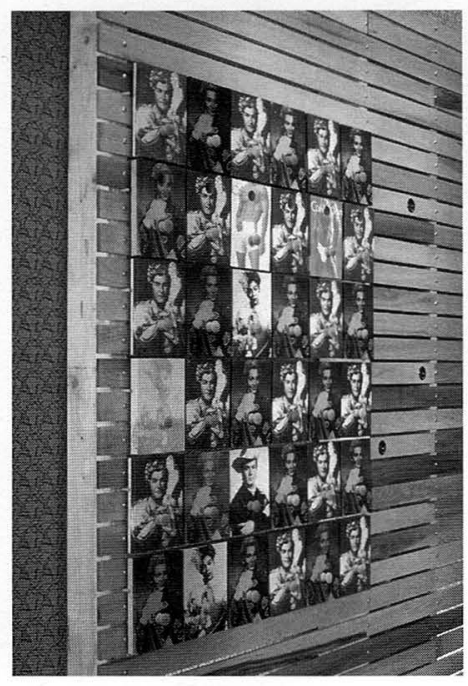

A shuttered passageway provides the other edge for this space, and rests against the high green floral wallpaper wall. Its dimension repeats the configuration of the built-in museum case that has been partially covered at the other end of the gallery. It is a purposely narrow path, with louvers on one side and a series of horizontal slats on the other, enforcing a certain intimacy for passersby. Entry into this corridor trips an audio loop of an operatic excerpt which alternates with night sounds of crickets.

